Article

\title{
Penentuan Kondisi Optimum Adsorpsi Kromium (III) Menggunakan Biosorben dari Limbah Kulit Nangka (Artocapus heterophyllus)
}

\author{
Karina Ardiani, Arifah Nur Raya, Inayati* \\ Jurusan Teknik Kimia, Teknik, Universitas Sebelas Maret, Jl. Ir. Sutami No.36A, Jebres, Kota Surakarta, \\ Jawa Tengah 57126 \\ E-mail: inayati@staff.uns.ac.id (Corresponding author)
}

\begin{abstract}
The purposes of the research are determine the optimum condition and the maximum adsorpstion of $\mathrm{Cr}$ (III) by biosorben from jackfruit peel. The process of the adsorption was started by to put 0.03 grams jackfruit peel adsorben to $\mathrm{Cr}\left(\mathrm{NO}_{3}\right)_{3}$ solution $2.5 \mathrm{ppm}$. The variables of the research are activation time, contact time between the adsorben and the solution, and $\mathrm{pH}$ of the solution. The sample was analyzed by Absorption Spectrophotometre (AAS) to show the Cr (III) concentration on the solutions. The optimum condition was reached at $5 \mathrm{pH}$ level with 50 minute of contact times and 24 hours activation time. The analysis results that the adsorption follows Langmuir Isoterm showed by the determinant value $\left(\mathrm{R}^{2}\right)$. The maximum power adsorption is $1.227 \mathrm{mg} / \mathrm{gram}$ adsorben
\end{abstract}

Keywords: adsorption, jackfruit peel, Cr (III), optimum condition

EQUILIBRIUM Volume 16 No.1 Januari 2017

Online at http:/ / equilibrium.ft.uns.ac.id 


\section{Pendahuluan}

Dewasa ini Indonesia semakin berkembang, yang ditandai dengan semakin banyaknya industri yang berdiri. Banyaknya industri tentunya memiliki dampak positif dan negatif. Dampak positifnya adalah pendapatan negara yang meningkat, dan jumlah pengangguran yang menurun, sedangkan dampak negatifnya adalah banyak industri yang tidak memperhatikan pengolahan limbah dari industri yang didirikan. Hal ini dapat dilihat dari banyaknya pencemaran lingkungan yang terjadi di daerah kawasan industri seperti di Jakarta atau kota besar lain.

Salah satu contoh pencemaran lingkungan yang sering terjadi di kawasan industri adalah pencemaran air akibat kontaminasi logam berat. Adapun logam berat yang sering menjadi kontaminan antara lain: merkuri $(\mathrm{Hg})$, kromium $(\mathrm{Cr})$, timbal $(\mathrm{Pb})$, arsen $(\mathrm{As})$, cuprum $(\mathrm{Cu})$, kadmium $(\mathrm{Cd})$, dan nikel (Ni). Meskipun konsentrasi logam berat tersebut kecil, apabila terakumulasi dan mengendap di dalam tubuh, maka akan sangat berbahaya bagi kesehatan (Pranoto, 2016).

Logam berat kromium (Cr) banyak ditemukan di kawasan industri tekstil penyamakan kulit, pelapisan logam dan cat. Berdasarkan keputusan menteri Lingkungan Hidup No: KEP-03/MENLH/2010 mutu baku air limbah untuk kawasan industri konsentrasi kromium total adalah $1 \mathrm{mg} / \mathrm{L}$, sedangkan apabila kandungannya melebihi ketentuan harus dihilangkan terlebih dahulu sebelum dibuang ke lingkungan (Diantari dkk., 2008).

Cara penghilangan limbah telah banyak diteliti. Salah satu cara yang banyak digunakan untuk penghilangan logam adalah metode adsorpsi. Adsorpsi merupakan proses penjerapan molekul yang terlarut dalam suatu larutan. Metode ini banyak digunakan karena mudah dan murah, dimana adsorben yang digunakan bisa berasal dari bahan dilingkungan sekitar.

Tujuan penelitian ini adalah mengetahui kemampuan limbah kulit nangka sebagai adsorben untuk menjerap logam berat jenis $\mathrm{Cr}(\mathrm{III})$, selain itu untuk mengetahui kondisi optimum adsorben ini melakukan penjerapan.

\section{Metode Penelitian}

1. Bahan Penelitian

Bahan-bahan yang digunakan antara lain: kulit nangka, $\mathrm{HCl}, \mathrm{NaOH}$, aquades, kromium nitrat $\left(\mathrm{Cr}\left(\mathrm{NO}_{3}\right)_{3}\right)$

2. Peralatan Penelitian

Peralatan yang digunakan dalam penelitian ini antara lain: timbangan listrik, oven, $\mathrm{pH}$ indikator, dan magnetic stirrer. Analisa daya jerap adsorben menggunakan Atomic Absorption Spectrophotometre (AAS).

3. Prosedur Penelitian

a. Pembuatan adsorben

Kulit nangka dibersihkan dan diambil bagian daging kulit yang berwarna putih, lalu dihaluskan menggunakan blender. Bubur kulit nangka yang dihasilkan disaring untuk memisahkan kulit nangka dengan air yang terkandung. Untuk adsorben tanpa aktivasi hasil penyaringan berupa bubur kulit nangka tadi langsung dikeringkan dalam oven selama 24 jam. Sedangkan untuk adsorben dengan aktivasi $\mathrm{NaOH}$, terlebih dahulu bubur kulit nangka setelah dihaluskan dicampur dengan larutan $\mathrm{NaOH} 2 \%$ selama 24 jam. Setelah itu disaring, dan hasil penyaringannya dikeringkan dalam oven selama 24 jam. Adsorben yang sudah kering dihaluskan sebelum digunakan sebagai adsorben dalam proses adsorpsi.

b. Pengontakkan Adsorben dengan larutan $\mathrm{Cr}\left(\mathrm{NO}_{3}\right)_{3} 2,5 \mathrm{ppm}$

1) Membuat larutan $\mathrm{Cr}\left(\mathrm{NO}_{3}\right)_{3} 2,5 \mathrm{ppm}$ dengan variasi $\mathrm{pH} 2,5$, dan 8 dengan cara menambahkan $\mathrm{HCl}$ ataupun $\mathrm{NaOH}$.

2) Mengambil $15 \mathrm{~mL}$ larutan $\mathrm{Cr}\left(\mathrm{NO}_{3}\right)_{3} 2,5 \mathrm{ppm}$ untuk masing- masing $\mathrm{pH}$ kemudian dicampurkan adsorben sebanyak 0,03 gram. Kemudian dilakukan pengadukan dengan magnetic stirrer dengan variasi waktu kontak 10, 30, dan 50 menit.

3) Setelah proses adsorpsi selesai, larutan sampel disaring menggunakan penyaring whattman untuk memisahkan larutan dengan adsorben.

c. Pengujian

Pengujian dilakukan untuk setiap sampel dengan variasi aktivasi adsorben, $\mathrm{pH}$ dan waktu kontak.

Pengujian sampel ini menggunakan AAS. 


\section{Hasil dan Pembahasan}

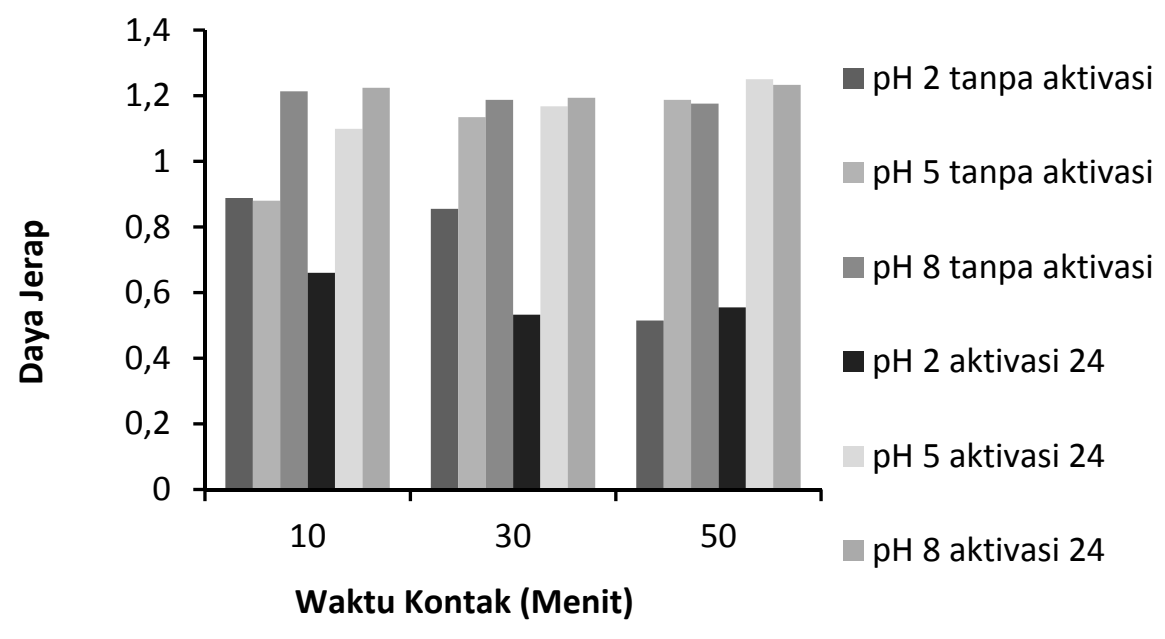

Gambar 1. Daya Jerap vs Waktu Kontak

1. Penentuan Kondisi Optimum

Kemampuan penjerapan suatu larutan oleh adsorben dapat dipengaruhi oleh $\mathrm{pH}$ larutan. Hal ini berhubungan dengan protonasi atau deprotonasi sisi aktif permukaan adsorben (Nurhasni, 2002). Sedangkan menurut Riapanitra (2006), $\mathrm{pH}$ berpengaruh pada muatan permukaan adsorben, derajat ionisasi, dan juga spesi yang terjerap dalam adsorpsi.

Berdasarkan data yang tersaji dalam diagram (gambar 1) terlihat bahwa semakin tinggi $\mathrm{pH}$ suatu larutan, maka semakin besar pula daya jerap adsorben. Hal ini berarti semakin banyak ion Cr (III) yang terjerap oleh adsorben. Penyebabnya adalah kadar ion $\mathrm{H}+$ dalam larutan semakin menurun seiring dengan bertambahnya $\mathrm{pH}$ larutan, sehingga semakin banyak $\mathrm{Cr}$ (III) yang terjerap di permukaan adsorben. Terlihat pula dalam diagram (gambar 1) bahwa saat $\mathrm{pH}$ basa $(\mathrm{pH} 8)$ terjadi penurunan daya jerap adsorben, hal ini disebabkan oleh adanya ion-ion logam yang membentuk endapan hidroksida sehingga mempersulit proses adsorpsi (Refilda, 2001). Berdasarkan analisa diatas dan juga data yang tersaji dalam diagram (gambar 1), maka dapat disimpulkan bahwa kondisi optimum dalam proses adsorpsi Cr (III) dengan adsorben kulit nangka ini terjadi saat pH 5 dengan waktu kontak 50 menit dan menggunakan adsorben kulit nangka dengan aktivasi 24 jam.

2. Penentuan Jenis Isoterm Adsorpsi

Isoterm dalam adsorpsi ada dua yaitu isoterm Langmuir dan isoterm Freundlich. Pemilihan jenis isoterm ini berhubungan dengan pendekatan persamaan yang digunakan untuk menentukan daya jerap dalam adsorpsi. Penentuan jenis isoterm tergantung pada harga koefisien determinan (R2), dimana dipilih jenis isoterm yang memiliki nilai R2 paling tinggi. 


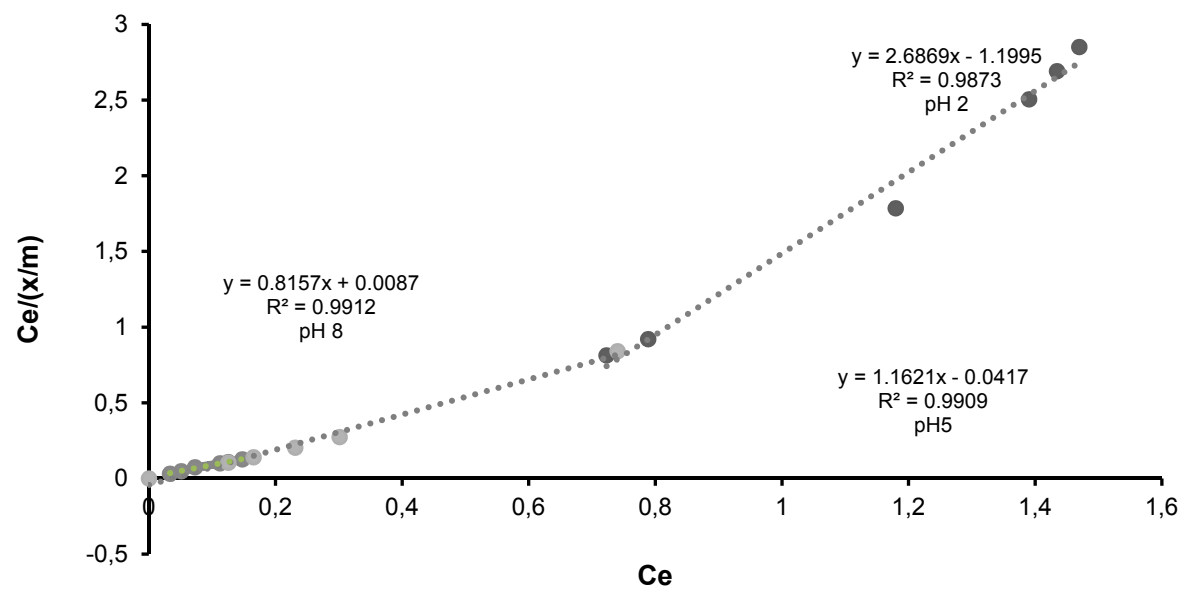

Gambar 2. Grafik Ce/(x/m) vs Ce untuk Menentukan Konstanta Persamaan Langmuir

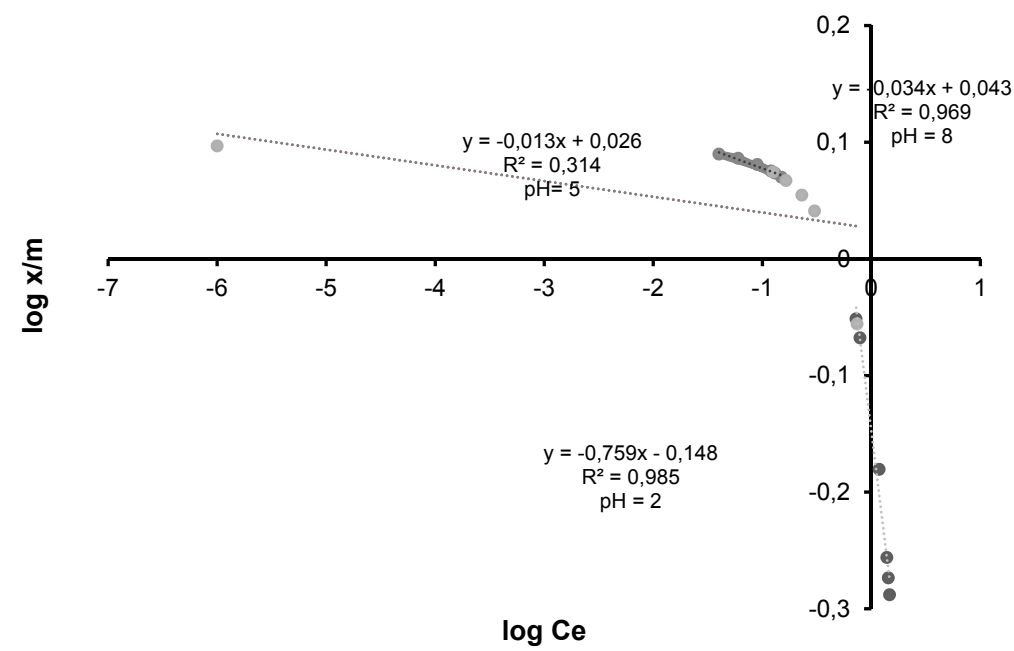

\section{Gambar 3. Grafik Log $\mathrm{x} / \mathrm{m}$ vs Log Ce untuk Menentukan Konstanta Persamaan Freundlich}

Berdasarkan gambar 2. dan gambar 3. terlihat bahwa adsorpsi Cr (III) dengan menggunakan kulit nangka ini cenderung mengikuti pendekatan isoterm Langmuir. Hal ini dikarenakan harga koefisien determinan $\left(\mathrm{R}^{2}\right)$ bernilai lebih tinggi, dimana untuk Langmuir $\mathrm{R}^{2}=0,9912$ sedangkan untuk Freundlich $\mathrm{R} 2$ $=0,9853$. Sehingga untuk menentukan daya jerap nya menggunakan pendekatan persamaan Langmuir.

Tabel 1. Harga Daya Jerap Absorben

\begin{tabular}{ccc}
\hline Isoterm & Konstanta & Harga \\
\hline Langmuir & $\mathrm{a}$ & 1,227 \\
& $\mathrm{~b}$ & 1,000 \\
Freundlich & $\mathrm{k}$ & 0,711 \\
& $\mathrm{n}$ & 1,318 \\
\hline
\end{tabular}

Dari tabel di atas dapat diketahui bahwa nilai daya jerap paling besar menggunakan isoterm Langmuir dengan besar daya jerap maksimum yaitu $1,227 \mathrm{mg} / \mathrm{g}$. 


\section{Kesimpulan}

1. Kondisi optimum proses adsorpsi logam Cr (III) dari larutannya dengan adsorben kulit nangka terjadi pada $\mathrm{pH} 6$ dengan waktu kontak 50 menit dengan menggunakan adsorben yang telah diaktivasi selama 24 jam.

2. Daya jerap maksimum yang dapat dicapai oleh adsorben kulit nangka untuk mengadsorpsi logam berat $\mathrm{Cr}$ (III) adalah $1,227 \mathrm{mg} / \mathrm{g}$ adsorben.

\section{Daftar Pustaka}

Diantariani, N.P, I W. Sudiarta dan N.K Elantiani, 2008, "Proses Biosorpsi dan Desorpsi Ion Cr (VI) pada Biosorben Rumput laut", Jurnal Kimia, 2 (1): 45-52

Edwin V. A., 2008, "Adsorption of $\mathrm{Ni}(\mathrm{II}), \mathrm{Cu}(\mathrm{II})$ and $\mathrm{Fe}(\mathrm{III})$ from Aqueous Solutions Using Activated Carbon", E-journal of Chemistry

Hameed, B. H., and Foo, K. Y. 2012. "Potential of Jackfruit Peel as Precursor for Activated Carbon Prepared by Microwave Induced $\mathrm{NaOH}$ Activation", Journal of Bioresource Technology

Hines, A. L, and Robert N, Maddoz, 1985, "Mass Transfer Fundamental and Applications", Prentice Hall Inc, New Jersey

Inbaraj, B. S., and Sulochana, N. 2006. "Use of Jackfruit Peel Carbon (JPC) for Adsorption of RhodamineB, a Basic Dye from Aqueous Solution". Indian Journal of Chemical Technology

Ikhuoria, E.U. and Onojie O.C., 2007, "Binding Nickel and Zinc Ions with Activated Carbon Prepared from Sugar Cane Fibre (Saccharum officinarum L.)", Journal of Applied Sciences

Edwin V. A., 2008, "Adsorption of $\mathrm{Ni}(\mathrm{II}), \mathrm{Cu}(\mathrm{II})$ and $\mathrm{Fe}(\mathrm{III})$ from Aqueous Solutions Using Activated Carbon", E-journal of Chemistry

Hameed, B. H., and Foo, K. Y. 2012. "Potential of Jackfruit Peel as Precursor for Activated Carbon Prepared by Microwave Induced $\mathrm{NaOH}$ Activation", Journal of Bioresource Technology

Hines, A. L, and Robert N, Maddoz, 1985, "Mass Transfer Fundamental and Applications", Prentice Hall Inc, New Jersey

Inbaraj, B. S., and Sulochana, N. 2006. "Use of Jackfruit Peel Carbon (JPC) for Adsorption of RhodamineB, a Basic Dye from Aqueous Solution". Indian Journal of Chemical Technology

Ikhuoria, E.U. and Onojie O.C., 2007, "Binding Nickel and Zinc Ions with Activated Carbon Prepared from Sugar Cane Fibre (Saccharum officinarum L.)", Journal of Applied Sciences 